\title{
PMIP: Looking back to its first phase
}

Sylvie Joussaume ${ }^{1}$ and Karl E. Taylor ${ }^{2}$

\author{
The Paleoclimate Modelling Intercomparison Project celebrates its 30th anniversary in 2021. The first phase initiated \\ systematic model-model and model-data comparisons for the Last Glacial Maximum and Mid-Holocene. Here, we \\ describe the historical context of PMIP, the experiment design, and the project's early impacts.
}

\section{PMIP Launch}

The Paleoclimate Modelling Intercomparison Project (PMIP) was launched 30 years ago at an international North Atlantic Treaty Organization (NATO; nato.int) workshop in Saclay, France, in 1991. Its main objectives were to investigate the mechanisms of climate change and to evaluate model capabilities in simulating past climates. At this workshop, the first PMIP experiments were conceived, which focused on two very different climatic periods: the Last Glacial Maximum (LGM; 21,000 years before present (BP)) with extremely cold conditions and the mid-Holocene $(6,000$ years BP) with an orbitally-forced change in seasonal cycle.

PMIP built on ground-breaking paleoclimate experiments performed with earlier models and capitalized on well-documented data syntheses for these periods, notably the extensive work of the Cooperative Holocene Mapping Project (COHMAP) group led by John Kutzbach. In the initial phase of the project, the main features of the selected paleoclimates were investigated by offering an experimental protocol where all models would be run with the same prescribed boundary conditions. From the start, PMIP was endorsed by both the International Geosphere Biosphere Program through PAGES and the World Climate Research Programme (WCRP; wcrp-climate. org), first through the Working Group on Numerical Experimentation and later by the Working Group on Coupled Modelling as part of Climate and Ocean - Variability, Predictability, and Change (CLIVAR; clivar. org).

During its first phase (1991-2001), PMIP focused only on atmospheric general circulation models (AGCMs), which at that time were the standard climate models. The final design of the PMIP experiments was only arrived at following intense discussions that began with the initial 1991 NATO workshop with a focus on the experimental design for the LGM. A major point of contention was whether to constrain the PMIP simulations of the LGM by prescribing sea surface temperatures (SSTs) as reconstructed by the Climate: Long range Investigation, Mapping, and Prediction (CLIMAP) project in 1981, with the prospect that the resulting climate would be more realistic, or to use AGCMs coupled to slab oceans, allowing for some surface ocean interactions, but with ocean horizontal heat transport fixed as present-day and, therefore, inconsistent with paleoclimate data. Each of these approaches had its proponents and its merits, and in the end, both were endorsed as options for the LGM.

For the mid-Holocene experiment, the choice of surface boundary conditions was easier since SSTs are nearer to present-day conditions. In this case, to help isolate the impact of orbital changes, the SSTs were simply prescribed to be the same as in the Atmospheric Modelling Intercomparison Project (AMIP) experiments. In the few years following the first workshop, consensus was reached concerning the LGM ice-sheet boundary conditions; the Peltier ice-sheet reconstruction was adopted in 1992 following discussions at a workshop at LamontDoherty Earth Observatory, USA, organized by Bill Ruddiman. Considerable work was required to iron out details concerning definition of the insolation forcing for the mid-Holocene and the proper way to compare seasonal cycles from past and present climates when statistics are based on civil calendar months, but climate responds to astronomically-determined seasons.

From the beginning, PMIP modelers and the paleoclimate data community forged a strong working relationship, as this had been key to the success of COHMAP. Thus, one of PMIP's many objectives was to encourage data syntheses for the two paleoclimate periods that would enable model-data comparisons. A model-data sub-committee organized this work, led by Sandy Harrison, Joël Guiot and Pat Bartlein. At a workshop in Aussois, France, in 1993, participants discussed both inverse and forward approaches for evaluating models using paleoclimate observations. These discussions highlighted the importance of fostering close interactions between the two communities.

By 1994, all experimental conditions were fixed and described in a foundational paper by Joussaume and Taylor (1995). This first phase of PMIP attracted the participation of 18 modeling groups, from Europe, the USA, Canada, Australia, Russia, Korea, and Japan. Following the lead of its slightly older sibling AMIP, PMIP relied on infrastructure support from the Program for Climate Model Diagnosis \& Intercomparison (PCMDI; pcmdi.Inl.gov) and its director, Larry Gates. In PMIP's first phase, data were collected and stored at PCMDI in a restricted-access database, as was the practice for AMIP as well. Several papers were published (see

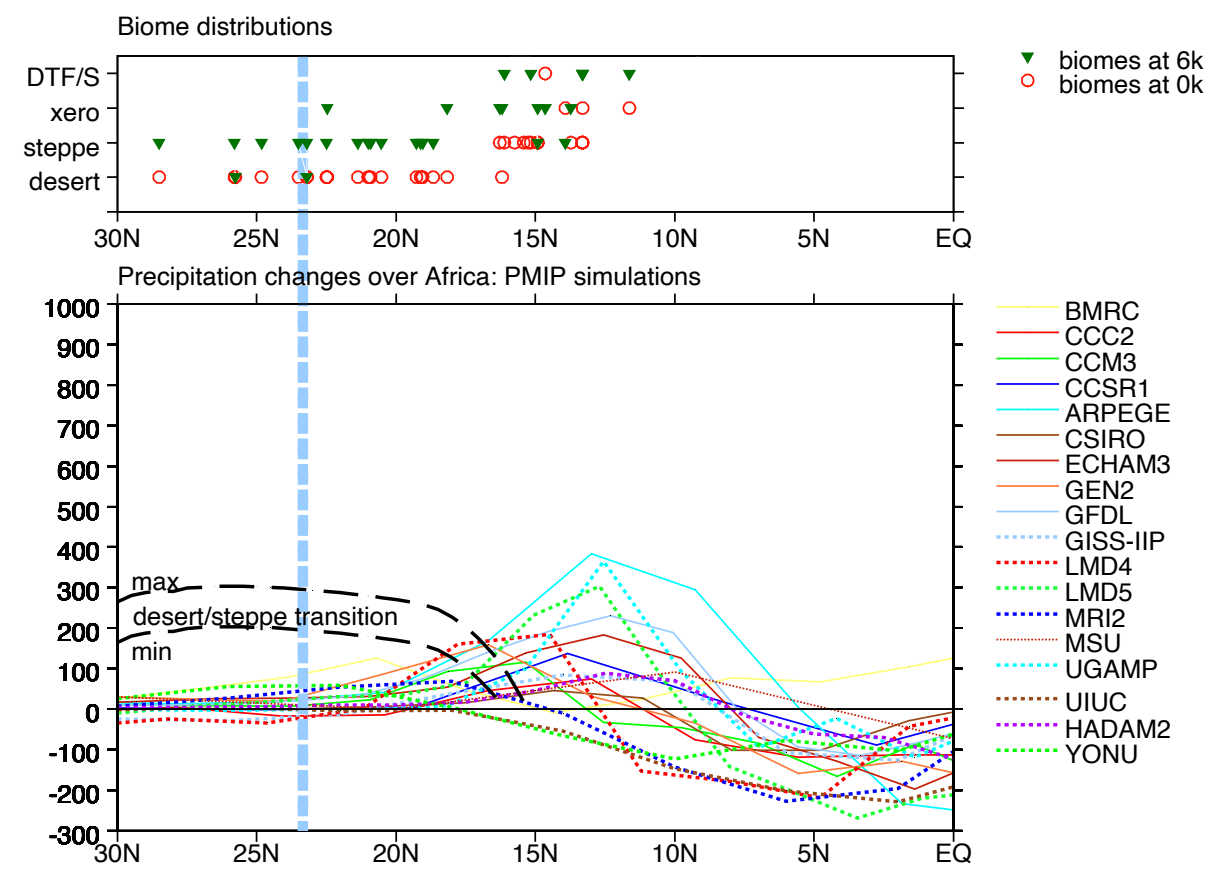

Figure 1: PMIP1 simulations of annual mean precipitation changes ( $6 \mathrm{kyr} \mathrm{BP}$ minus present; $\mathrm{mm} /$ year) in the African monsoon region $\left(20^{\circ} \mathrm{W}-30^{\circ} \mathrm{E}\right)$. (A) Biome distribution (desert, steppe, xerophytic and dry tropical forest/ savannah; DTF/S) as a function of latitude for $6 \mathrm{kyr} \mathrm{BP}$ (green triangles) and present-day (red circles). The limit of desert-steppe at $6 \mathrm{kyr} \mathrm{BP}$ around $23^{\circ} \mathrm{N}$ (blue vertical dashed line) provides a range of precipitation excess above model results shown in (B). (B) Model results with hatched lines showing estimated upper and lower bounds excess precipitation needed to support grasslands based on present climatic limits. Figure reproduced from McAvaney et al. (2001); redrawn from Joussaume et al. (1999). 


\section{Model-data comparison at the LGM $\left(30^{\circ} \mathrm{N}-30^{\circ} \mathrm{S}\right)$}

\section{(LGM - PD) temperature differences}
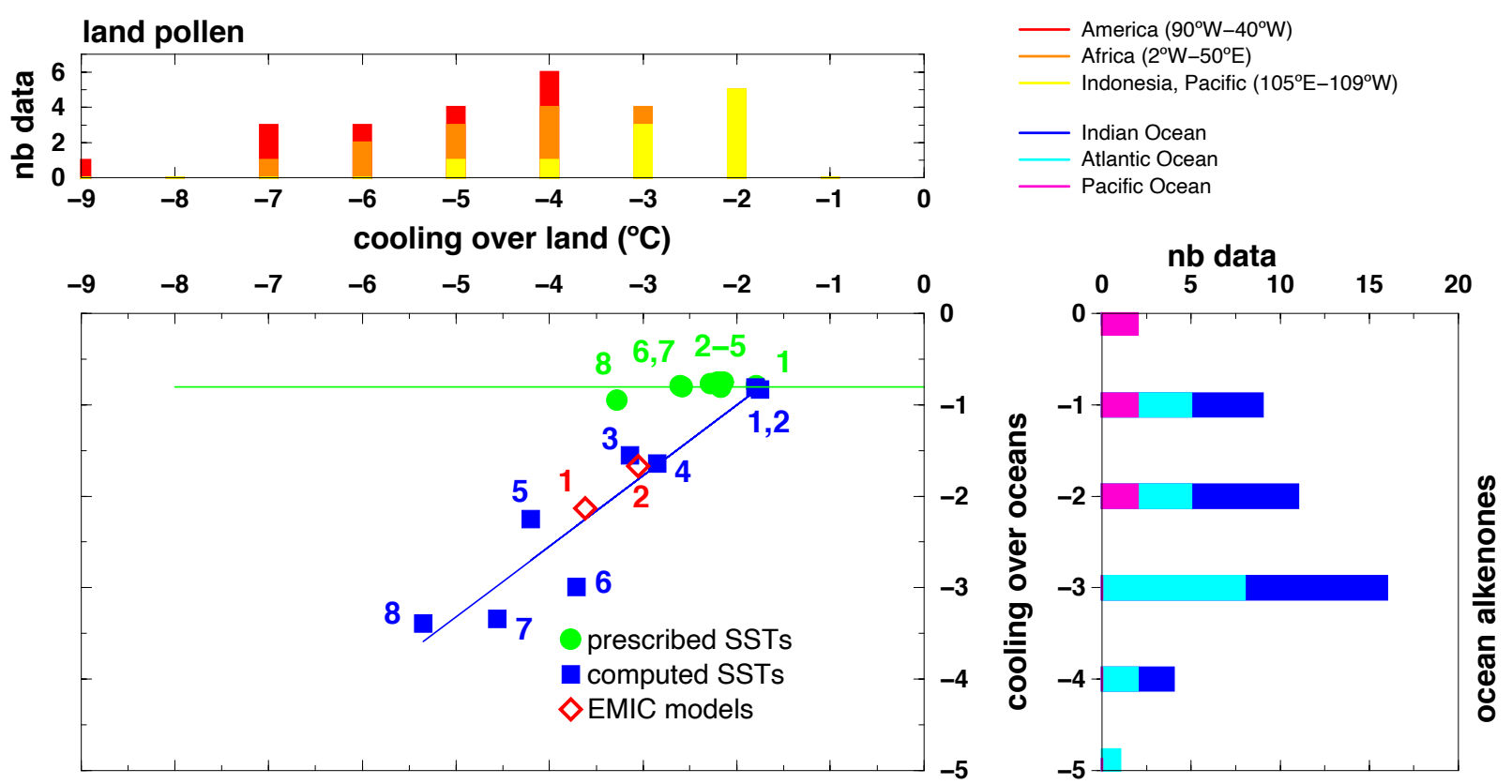

Figure 2: Annual mean simulated tropical cooling over ocean and land from PMIP1 LGM simulations, compared to estimates of terrestrial cooling from pollen (Farrera et al. 1999) and from ocean SSTs estimated from alkenones (Rosell-Melé et al. 1998). Figure reproduced from McAvaney et al. (2001; adapted from Pinot et al. 1999).

pmip1.Isce.ipsl.fr), and the major findings were emphasized in the third IPCC Assessment Report (McAvaney et al. 2001). Two key PMIP figures are reproduced here in Figures 1 and 2 .

PMIP results became the focus of several community workshops that included both paleoclimate modelers and specialists in paleoclimate data. At the first workshop in 1995 in Collonges-la-Rouge, France, initial analyses were shared. Then in 1997 at San Damiano, USA, subprojects were organized and papers planned. Subsequently, in 1999 at La Huardière, Canada, a synthesis of the results was prepared and then published in a WCRP special report (Braconnot 2000). These workshops have been essential to PMIP's success. They were instrumental in developing the close working relationship between modelers and data specialists that led to a better appreciation of the limitations of both models and observations and to development of improved understanding of the climate system. The PMIP workshops have all been intensive, interactive, and lively; and we will not forget the "PMIP song" introduced in the Collonges-la-Rouge workshop (pmip1.Isce.ipsl.fr/goodies/song. html), and revised in San Damiano; and the dancing and revelry in La Huardière!

\section{Main highlights from the first PMIP phase} In what became known as the "Big Picture Paper", Joussaume et al. (1999) showed that as a result of increased summer insolation, all the models simulated an increase in the summer monsoon precipitation over Africa and Asia during the mid-Holocene (Fig. 1). A quantitative comparison over Africa using results from BIOME 6000 (Jolly et al. 1998) showed that all the models underestimated the northward displacement of the desertsteppe transition, which was also confirmed by vegetation simulations using PMIP outputs (Harrison et al. 1998). This is a modeling problem that continues to challenge stateof-the-art models.

The model-data comparisons over Europe led to the establishment of new bioclimatic variables such as temperature of the coldest month and growing degree-days, rather than the commonly-used January and July temperature estimates (Cheddadi et al. 1996). These more robust variables enhance confidence in model-data comparisons (Masson et al. 1999).

For the LGM, models simulated a global cooling of about $4^{\circ} \mathrm{C}$ when forced with CLIMAP SST reconstructions, whereas AGCMs coupled to slab oceans produced a global cooling between $2^{\circ}$ and $6^{\circ} \mathrm{C}$. Following the issue raised by Rind and Peteet (1985) about the underestimation of the simulated terrestrial tropical cooling at LGM, a detailed model-data comparison study was conducted for the tropics that relied on a new data synthesis effort fostered by PMIP (Farrera et al. 1999). In the tropics, models forced by the relatively warm CLIMAP SSTs confirmed an underestimated terrestrial cooling, whereas models that computed SSTs obtained estimates in better agreement with the observed tropical cooling (Fig. 2), compensating for their relatively weak cooling over land with excessive ocean cooling (Pinot et al. 1999). In addition, an extensive comparison over Europe (Kageyama et al. 2001) concluded that according to pollen data (Peyron et al. 1998), models tended to underestimate winter cooling, at least over western Europe.

\section{Looking forward}

When launching PMIP in 1991, we did not expect the project would still be relevant, let alone vibrant, 30 years later. During this time, younger scientists have brought new energy and ideas to the project, and have reinvigorated the quest to understand paleoclimates. We believe that PMIP will continue to attract a community of researchers who enjoy working together and who will seize opportunities to expand our knowledge of our climate system by looking at the past.

\section{AFFILIATIONS}

'Laboratoire des Sciences du Climat et de

I'Environnement, LSCE/IPSL, UMR CEA-CNRS-UVSO, Université Paris-Saclay, Gif sur Yvette, France 2PCMDI, Lawrence Livermore National Laboratory, Livermore, CA, USA

CONTACT

Sylvie Joussaume: sylvie.joussaume@|sce.ipsl.fr

REFERENCES

Braconnot P. (Ed; 2000) Paleoclimate Modelling

Intercomparison Project: proceedings of the third PMIP Workshop. WCRP-111, WMO/TD-1007, 271 $\mathrm{Pp}$

Cheddadi R et al. (1996) Clim Dyn 13: 1-9

Farrera l et al. (1999) Clim Dyn 15: 823-856

Harrison SP et al. (1998) J Clim 11: 2721-2742

Jolly D et al. (1998) J Biogeogr 25: 1007-1027

Joussaume S, Taylor KE (1995) Status of the paleoclimate modeling intercomparison project, Proceedings of the first international AMIP scientific conference, WCRP Report, 425-430

Joussaume S et al. (1999) Geophys Res Lett 26: 859-862 Kageyama M et al. (2001) Clim Dyn 17: 23-43

Masson V et al. (1999) Clim Dyn 15: 163-182

McAvaney BJ et al. (2001) In: J. Houghton (Ed) Climate Change 2001: The Scientific Basis. Cambridge

University Press, 471-523

Peyron O et al. (1998) Quat Res 49: 183-196

Pinot S et al. (1999) Clim Dyn 15: 857-874

Rind D, Peteet D (1985) Quat Sci Rev 24: 1-22

Rosell-Melé A (1998) EOS 79: 393-394 